\title{
Evaluation of the awareness and utilization of oral rehydration salt and zinc in managing diarrhoea among under-five children in Oyo State, Nigeria.
}

Adeniyi Francis Fagbamigbe ( $\sim$ franstel74@yahoo.com )

University of Ibadan

Juma Joseph

Mount Kenya University

Alfred Owino

Mount Kenya University

Dominic Mogere

Mount Kenya University

John Kariuki

Mount Kenya University

Research Article

Keywords:

Posted Date: February 16th, 2022

DOI: https://doi.org/10.21203/rs.3.rs-1330715/v1

License: (c) (1) This work is licensed under a Creative Commons Attribution 4.0 International License.

Read Full License 


\section{Abstract}

Introduction: Despite the recommendation that a child having the symptoms of diarrhoea must be given Oral Rehydration Salt (ORS) and Paediatric Zinc Sulphate Dispersible Tablets (Zinc) within 24 hours of such notice, Nigeria ranks as one of the highest countries with the negative consequences of diarrhoea in sub-Saharan Africa (SSA). This study seeks to evaluate the awareness and utilization of ORS and zinc in managing diarrhoea among under-five children (U5C) in Oyo State, Nigeria.

Methods: Data was obtained from a cross-sectional survey $(n=1154)$ as well as focus group discussions (FGD) among mothers/caregivers of U5C and key informant interviews in Oyo State. Descriptive, bivariate and multivariate logistic regression analyses were performed. The primary outcomes were awareness and utilization of ORS and zinc for managing a recent episode of diarrhoea. The level of significance was set at 5\%. Data were analyzed with STATA 16.0 and Nvivo software.

Results: Nine of every ten caregivers were aware of the use of ORS/Zinc for managing diarrhoea cases. Prevalence of ever-use of ORS/Zinc for managing diarrhoea cases was $5.4 \%$ while the prevalence of having diarrhoea recently was $6.2 \%(71 / 1154)$. Of the 71 mothers whose U5C recently had diarrhoea, $41(57.7 \%)$ used ORS/zinc to manage a recent episode of diarrhoea. Adjusted odds of using ORS/Zinc to manage diarrhoea was $2.64(\mathrm{aOR}=2.64 ; 95 \%$ Confidence Interval $(\mathrm{Cl}): 1.18-10.27)$ times higher among children who are the first births (first-order) than those with fourth or higher birth order. The adjusted odds of using ORS/Zinc to manage diarrhoea was 9 times ( $\mathrm{aOR}=9.15 ; 95 \% \mathrm{Cl}: 1.99-34.47$ ) higher among mothers aged 20 to 24 years and 3.82 times ( $\mathrm{aOR}=3.82 ; 95 \% \mathrm{Cl}$ : $1.02-14.27)$ higher among mothers aged 25 to 29 years than those aged 30 to 39 years. Having problems accessing healthcare services was also significant. Some of the FGD participants claimed they have used ORS/zinc before.

Conclusion: Despite the high level of awareness of the use of ORS and Zinc in managing diarrhoea, everutilization is low but recent use by three-fifths of the caregivers is fair. Maternal age, children birth order and proximity to healthcare facilities are the key influencers. There is a need for Oyo State Ministry of Health and other stakeholders to promote the use of ORS and Zinc in managing diarrhoea.

\section{Introduction}

In 2016, diarrhoea was reported as the $5^{\text {th }}$ major child killer [1] and has been reported as the $9^{\text {th }}$ global leading cause of death - responsible for about $9 \%$ of the fatality rate among under-five children (U5C) [2, 3]. The diarrhoea mortality rate in U5C was highest in SSA and South Asia [2]. In particular, Nigeria ranks as one of the highest countries with the burden of diarrhoea among the sub-Saharan Africa (SSA) countries. The prevalence of diarrhoea related deaths in Nigeria was estimated at $18.8 \%$. This is clearly above the SSA's average of $16 \%$ (WHO, 2017).

Over 200,000 children in Nigeria die each year from diarrhoea-related illness, and most communities in the country have seen diarrhoea-related deaths as of 2018 [4]. This happened despite the recommendation of the UNICEF and WHO recommendation that Oral Rehydration Salt (ORS) and zinc 
should be used to treat the disease in infants and U5C [5]. A very low proportion of victims of diarrhoea were given the drugs, while others received suboptimal products like antibiotics and anti-diarrhoeas and in some cases, some children who had diarrhoea received no treatment [6-9]. The poor utilization has been ascribed to limited knowledge, high cost and availability of these drugs [6-9].

The burden of under-five morbidities and mortalities resulting from diarrhoea can be reduced significantly by at least $75 \%$ if the recommended treatment options by WHO and UNICEF are adequately taken. The recommendation was that a child having the symptoms of diarrhoea must be given Oral Rehydration Therapy (ORT) and Paediatric Zinc Sulphate Dispersible Tablets (Zinc) within 24 hours of such notice [5]. The ORT consists of fluid extracted from ORS packets or pre-packaged liquid and governmentRecommended Home Fluids (RHF). While the ORS and RHF could be used to treat and prevent diarrhoearelated dehydration, oral Zinc shortens the duration and the degree of severity of diarrhoea[6, 10]. Literature is replete that most of these mortalities are preventable $[11,12]$.

The utilization of ORS/Zinc for the management of diarrhoea varied both globally and in African continent. While 66\% was reported in South Africa, 57.6 was found in Tanzania, 73.3\% in Kazakhstan and $54.3 \%$ in Lesotho [13]. Only a third of the mothers in an India study used ORS for treating diarrhoea among U5C [14]. Carvajal-vélez et al. had found a median of 38\% prevalence of ORS use for the management of diarrhoea among 12 countries in Africa -Burkina Faso, Burundi, Cameroon, Cote d'Ivoire, Dr Congo, Ethiopia, Mali, Niger, Nigeria, Sierra Leone, Tanzania, and Uganda [15].

\section{Theoretical Framework}

We adopted the Andersen's Behavioural Model (BM) for this study $[16,17]$. The framework posited that factors that influence health care utilization are interrelated across environmental characteristics, individual characteristics, individual health behaviour and perceived health outcomes. According to Andersen, three main groups of factors (predisposing factors, enabling factors and the needs factors) affect health uptake $[16,18]$. The predisposing factors are the socio-cultural attributes of people that exist before their sickness. This consist of (i) social structures including education, employment, nationality, interpersonal organizations, social collaborations and interactions and culture (ii) health beliefs which include attitudes, qualities, values and information that individuals have concerning and towards the wellbeing framework in their domain and (iii) demographic structure such as age and gender.

The enabling factors are the logistics involved in obtaining care. It includes personal and family factors which the means, knowledge and ability to access healthcare, poverty, health insurance, source of care, travelling, extent, degree, quality and nature of social connections and interactions. Community factors such as availability of health care practitioners and facilities, response time and waiting time; and possible additions such as genetic factors and other psychological characteristics [17].

The need factors are the most cogent reasons and causes for the utilization of healthcare services. It covers functional and health problems that propel the need for health care services. Andersen stated that a perceived need for a health care service will help to understand the pattern of health care seeking and 
how patients adhere to medication. On the other way, the evaluated need will help determine the kind and volume of treatment provided to a patient after he/she has been seen by a provider. The perceived need describes how individuals see their overall health and functional state, in addition to how they experience manifestations of ailment, agony, worries, anxieties and stresses over their wellbeing and whether they judge their issues to be of adequate significance and magnitude to seek health assistance. The evaluated needs are based on health care providers' judgement on patients' status and need for medical care [19].

The Andersen model has been utilized widely in examining the use of health care services [20]. Babitsch et al. confirmed that the ABM has been utilized in several areas of health outcomes services. The theoretical framework is based on the Anderson framework for the use of healthcare services [17]. It has been cited in different literature Therefore, mothers/guardians' decision to use zinc/ORS in the management of diarrhoea among U5C in Oyo state, Nigeria may be influenced by different factors including the external environment, predisposing, enabling, needs, personal health practices factors and one's perceived health status as well as other external factors. In this study, the main exposure variable is the use of a health facility that is linked to the external environment, both the predisposing factors and the enabling factors and the need factors. The external environmental factors consist of the type of residence (Rural and Urban) and region (north, south, central). The predisposing factors are made up of the mother's current age, parental educational attainment, religion, access to media, child sex, birth order

and mother's employment status. The enabling factors were made up of the mother's autonomy to decide health care utilization, distance to the health facility and household wealth index. The child's age was used to measure the need factor [21]. A similar framework has been used in literature [22]. This study, therefore, evaluated the level of awareness of mothers and factors associated with the utilization of use of ORS and zinc in managing diarrhoea among U5C in Oyo State, Nigeria.

\section{Methods}

\section{Study Design}

A cross-sectional study design involving both qualitative and quantitative data was used. Questionnaires were used for the quantitative study while focus group discussion (FGD) and key informant interviews (KII) were used to collect the qualitative data.

\section{Study area}

This study was carried out in the Oyo State of Nigeria using a case study approach whereby the researcher actively engages the stakeholders during the research. Oyo state has the highest burden of diarrhoea in South-West Nigeria (Figure 1). One of every under 5 children in Oyo state experienced diarrhoea within two weeks [23]. The state has one tertiary hospital, 3 secondary hospitals and over 500 primary health facilities.

\section{Study population}


The study population consisted of U5C in regular households in the Oyo State of Nigeria. The study sample were mothers of the U5C in selected households across the state for the quantitative and the qualitative study.

\section{Sampling Strategy}

The sampling was a multi-stage cluster sampling. The most current (2006) Nigeria National Population and Housing Census for Oyo State was used as the sampling frame. The EAs are the clusters and are the primary sampling unit in this study. At the first stage, 2 LGAs were randomly selected from the LGAs in each senatorial district, then 5 clusters each were randomly selected from the selected LGAs. In the third stage, 25 households were randomly selected in each cluster, however, a household must have at least one under-five child to be selected. Households with no U5C were skipped. Finally, one under-five child each was selected from the already selected households that have more than one under-five child. Mothers of U5C currently or who had any other ailment besides diarrhoea within two weeks before the survey would not participate in the study. Further exclusion criteria were mental disorders or neuropsychological factors which could impede the capacity of the mothers to answer interview questions. The Two FGD and four KII participants were purposively sampled.

\section{Variables}

The conceptual framework that guided the choice of explanatory variables is shown in Figure 2.

The outcome variable is use of Zinc/ORS and management of diarrhoea among under 5 children. Guided by the theoretical and conceptual frameworks, the explanatory variables included sociodemographic characteristics, housing characteristics, household wealth tertiles etc. Full details are shown in Table 1. The guide for qualitative data contained questions on policies relating to the management of diarrhoea, knowledge, practices and availability of ORS and Zinc in health facilities and attitudes of health personnel towards the prescription of ORS and Zinc for management of diarrhoea among U5C.

\section{Data management and Statistical analysis}

A total of 1,154 mothers and guardians were interviewed for the quantitative study. Data were collected using a pretested semi-structured interviewer-administered questionnaire. Qualitative data was collected using FGD, KII and document reviews in Nigeria. Data was analysed in STATA version 17 while the qualitative data was analyzed in Nvivo 15. Basic descriptive statistics comprising mean, standard deviation, proportions, rates, ratios, and confidence intervals were used to summarize quantitative data and other categorical data. Bivariate tests of association between the dependent variable (utilization of ORS/Zinc) and the independent variables were carried out using chi-square tests. Statistical significance was considered at $p=0.05$.

\section{Results}


Of the 1,154 mothers/guardians who participated in the study, 14 (1.2\%) were aged 15 to 19 years, 2160 $(13.9 \%)$ were aged 20 to 24 years, while $324(28.1 \%)$ were aged 25 to 29 years. The majority, 1,118 $(96.9 \%)$, of the respondents were living with a sexual partner or currently married. A total of 946 respondents (82.0\%) are from male-headed households. About three quarters (845 (73.2\%)) resided in the urban areas while only $56.3 \%$ had no problem with distances to getting healthcare services. About $73 \%$ of the respondents could correctly identify the symptoms of diarrhoea while $6 \%$ of the children had a recent episode of diarrhoea (Table 1).

\section{Knowledge of symptoms of diarrhoea among mothers/guardians}

On the correct description of symptoms of diarrhoea, 839 (72.7\%) had good knowledge (Table 1). The characteristics that are significant with correct knowledge of symptoms of diarrhoea are marital status ( $p$-value $=0.006)$, partner's education ( $p$-value $=0.047)$, health care autonomy ( $p$-value $=0.000)$, and having a problem with distance to healthcare services $(p-v a l u e=0.000)$.

The outcome of the FGD and KIls showed that the discussants have a good knowledge of the symptoms of diarrhoea. According to the FGD, most of the discussants described what diarrhoea is. A mother aged 45 years, speaking Yoruba language, the predominant local language in the study area stated that

"It is "igbegbuuru". Meaning watery stool."

(Female, 45, FGD 1).

This description was further explained by a younger mother aged 24 years in the second FGD.

"Diarrhoea is when a child stools continuously for several days and the stool has water."

(Mother, 24, FGD 2).

However, another mother with a child of two years claimed that she doesn't know what diarrhoea is. She claimed that her child never had it so she doesn't know what it is.

"Diarrhoea? I don't know what it is ooo. My child never had anything like that."

(Mother, 19, FGD 2).

\section{Prevalence of diarrhoea among U5C}

Of the 1154 respondents, only 71 had diarrhoea within two weeks before the data collection, indicating overall prevalence of $6.2 \%$ (Table 1). The characteristics that were significant with likelihood of diarrhoea are maternal age ( $p$-value $=0.026)$, maternal education ( $p$-value $=0.015)$, partner's education ( $p$ value $=0.010)$, health care autonomy ( $p$-value $=0.015)$, and having problem with distance to healthcare services $(p$-value $=0.000)$ and place of residence $(p$-value $=0.006)$. 
Both the participants in the KII and FDG agreed that diarrhoea is common in the area. A 53-year-old Medical Director who works in a secondary-level hospital in Ibadan stated that he treats at least 8 children per week for diarrhoea.

"Yes, diarrhoea is common in this area. I treat at least 8 cases of diarrhoea every week."

(Medical Doctor, 53, KII 1)

His assertions were further confirmed by the Director of child care, Oyo State Ministry of Health, Ibadan. He stated that diarrhoea is a common childhood disease in the area and that government encourages mothers to report occurrences of diarrhoea to the nearest hospital as soon as it is noticed

"Yes, the government is aware of the problem of diarrhoea among under-five children in the state. The government encourages mothers to report occurrences of diarrhoea to the nearest hospital as soon as it is noticed"

(Director, $\mathrm{MoH}, 45, \mathrm{KII} 4)$

\section{Awareness of the use of ORS/Zinc for managing diarrhoea cases among U5C}

The overall level of awareness of the use of ORS/Zinc for managing diarrhoea cases among U5C was $90.6 \%$. The level was $64.3 \%$ among the mothers aged 15 to 19 years, $89.4 \%$ among mothers aged 20 to 24 years, $93.2 \%$ among mothers aged 25 to 29 years, $90.7 \%$ among those aged 30 to 39 years and $87.8 \%$ among those aged 40 years or more. Also, all the formerly married women claimed to be aware of the use of ORS/Zinc compared with $80.0 \%$ among the never married and $90.6 \%$ among those living with sexual partners (Table 1).

Most discussants in the two FGDs were unanimous in their agreement that they are aware that ORS could be used to treat and properly manage diarrhoea episodes among U5C.

"I have heard about ORS and Zinc and have even used it before when my child had diarrhoea last year",

(Mother, 38, FGD 2)

"I have bought it from a chemist near my house before. I have used it for my son when he was 3 and half years"

(Woman, 32, FGD 1)

Some of the respondents claimed that they have never heard about ORS and Zinc. "No, I don't know ORS or Zinc. I never hear about it"

(Woman, 23, FGD 1) 
The officials from the Ministry of Health and the local hospitals claimed that ORS and Zinc is well known in the state and that it is usually advertised, given and promoted among pregnant women in the study area.

"Most people are aware of the need to use ORS and Zinc to treat diarrhoea in Oyo State because we are always announcing it on radio and television"

(Director, $\mathrm{MoH}, 45, \mathrm{KII} 4$

"We show it to all nursing mothers during our maternity meetings. The mothers are educated on how to use it. They are always reminded that they can get it from local chemists and shops when their children has diarrhoea."

(Female Medical Doctor, 37 years, KII 2)

Some of the discussants in the FGDs reported the use of ORS and Zinc in managing diarrhoea episodes among U5C.

"I have used ORS and Zinc before when my child had diarrhoea last year",

(Mother, 38, FGD 2)

"I have used it for my son, when he was 3 and half years"

(Mother, 32, FGD 1)

However, some of the respondents claimed that they have never used ORS and Zinc to treat or manage diarrhoea.

"No, I don't know ORS or Zinc. So I never use am before"

(Guardian, 44, FGD 1)

"I have heard about it but I never use am, as none of my children had diarrhoea"

(Mother, 18, FGD 2)

\section{Use of ORS/Zinc for managing diarrhoea cases among U5C}

The overall prevalence of ever-use of ORS/Zinc for managing diarrhoea cases among U5C was $5.4 \%$ as shown in Table 2. The prevalence of ever-use of ORS/Zinc for managing diarrhoea cases among U5C was $0.0 \%$ among the mothers aged 15 to 19 years, $8.1 \%$ among mothers aged 20 to 24 years, $10.5 \%$ among mothers aged 25 to 29 years, $2.3 \%$ among those aged 30 to 39 years and also among those aged 40 years or more. Also, none of the never-married and formerly married women claimed to have ever used ORS/Zinc compared with $5.5 \%$ among those living with sexual partners. 
Some of the discussants in the FGDs reported the use of ORS and Zinc in managing diarrhoea episodes among under-five children.

"I have used ORS and Zinc before when my child had diarrhoea last year",

(Mother, 38, FGD 2)

"I have used it for my son, when he was 3 and half years"

(Mother, 32, FGD 1)

However, some of the respondents claimed that they have never used zinc and ORS to treat or manage diarrhoea.

"No, I don't know ORS or Zinc. So I never use am before"

(Guardian, 44, FGD 1)

"I have heard about it but I never use am, as none of my children had diarrhoea"

(Mother, 18, FGD 2)

About half (54.9\%) of the respondents claimed to have used something to manage diarrhoea recently. Thirty-eight of the 71 (53.5\%) mothers who reported a recent episode of diarrhoea among their U5C claimed to have used ORS to manage the episode Table 3. The prevalence of recent ORS use for male children was $51.2 \%$ and $56.7 \%$ among female children ( $p$-value $=0.649)$ and higher $(n=23(62.2 \%))$ among children aged 7 to 23 months compared with $37.5 \%$ and $46.2 \%$ for children aged 0 to 6 and 24 to 59 months respectively ( $p$-value $=0.286$ ). A total of 22 of the 71 mothers who reported a recent episode of diarrhoea among their U5C claimed to have used Zinc to manage the episode. Two thirds ( 41 of the 71 (57.7\%) mothers who reported a recent episode of diarrhoea among their U5C) claimed to have used ORS or Zinc to manage the episode of diarrhoea. The prevalence of recent use of either ORS or Zinc use for male children was $56.1 \%$ and $60.5 \%$ among female children and $n=25(67.6 \%)$ ) among children aged 7 to 23 months compared with $50.0 \%$ and $46.2 \%$ for children aged 0 to 6 and 24 to 59 months respectively. Also, the use increased with a higher number of dejure members of each household with $51.9 \%$ for only 1 usual member, $57.1 \%$ for 2 usual members and $77.8 \%$ for 3 or more usual members of the households (Table 3). A total of 19 of the 71 (26.8\%) mothers who reported recent episode of diarrhoea among their U5C claimed to have used both ORS and Zinc to manage the most recent episode of diarrhoea cases among U5C. The prevalence among male children was $31.7 \%$ and $20.0 \%$ among female children ( $p$ value $=0.271$ ) and $35.1 \%$ among children aged 7 to 23 months compared with $12.5 \%$ and $19.2 \%$ for children aged 0 to 6 and 24 to 59 months respectively ( $p$-value $=0.234$ ).

Table 1: Distribution of study participants by maternal characteristics, knowledge of symptoms, recent episode, and level of awareness of the use of ORS/Zinc for managing diarrhoea 


\begin{tabular}{|c|c|c|c|c|c|c|}
\hline Characteristics & $\mathbf{N}$ & $\%$ & $N(\%)$ & $\begin{array}{l}\text { Knows } \\
\text { Diarrhoea } \\
\text { symptoms }\end{array}$ & $\begin{array}{l}\text { Recently } \\
\text { had } \\
\text { Diarrhoea }\end{array}$ & $\begin{array}{l}\text { Aware of } \\
\text { ORS/Zinc }\end{array}$ \\
\hline
\end{tabular}

\section{Maternal Age (years)}

$\begin{array}{lllllll}15-19 & 14 & 1.2 & 14(1.2) & 10(71.4) & * 0(0.0) & * 9(64.3) \\ 20-24 & 160 & 13.9 & 160(13.9) & 118(73.8) & 11(6.9) & 143(89.4) \\ 25-29 & 324 & 28.1 & 324(28.1) & 231(71.3) & 31(9.6) & 302(93.2) \\ 30-39 & 525 & 45.5 & 525(45.5) & 386(73.5) & 23(4.4) & 476(90.7) \\ 40-49 & 131 & 11.4 & 131(11.4) & 94(71.8) & 6(4.6) & 115(87.8)\end{array}$

\section{Marital status}

\begin{tabular}{lllllll} 
Never Married & 20 & 1.7 & $20(1.7)$ & $* 15(75.0)$ & $1(5.0)$ & $16(80.0)$ \\
$\begin{array}{l}\text { Living with sexual } \\
\text { partner }\end{array}$ & 1,118 & 96.9 & $1118(96.9)$ & $818(73.2)$ & $70(6.3)$ & $\begin{array}{c}1013 \\
(90.6)\end{array}$ \\
$\begin{array}{l}\text { Formerly } \\
\text { Maternal Education }\end{array}$ & 16 & 1.4 & $16(1.4)$ & $6(37.5)$ & $0(0.0)$ & $16(100.0)$ \\
\hline None & 172 & 14.9 & $172(14.9)$ & $128(74.4)$ & $* 3(1.7)$ & $* 120$ \\
\hline Primary & 201 & 17.4 & $201(17.4)$ & $139(69.2)$ & $10(5.0)$ & $181(90.0)$ \\
\hline Secondary+ & 781 & 67.7 & $781(67.7)$ & $572(73.2)$ & $58(7.4)$ & $744(95.3)$ \\
\hline Partner Education & & & & & & \\
\hline None & 193 & 17.3 & $193(17.3)$ & $* 155(80.3)$ & $* 4(2.1)$ & $* 148$ \\
\hline Primary & 155 & 13.9 & $155(13.9)$ & $109(70.3)$ & $7(4.5)$ & $137(88.4)$ \\
\hline Secondary+ & 767 & 68.8 & $767(68.8)$ & $553(72.1)$ & $59(7.7)$ & $727(94.8)$ \\
\hline Religion & & & & & & \\
\hline Catholic & 536 & 46.4 & $536(46.4)$ & $396(73.9)$ & $32(6.0)$ & $485(90.5)$ \\
\hline Islam & 618 & 53.6 & $618(53.6)$ & $443(71.7)$ & $39(6.3)$ & $560(90.6)$ \\
\hline
\end{tabular}

Tribe

\begin{tabular}{lllllll} 
Hausa/Fulani & 55 & 4.8 & $55(4.8)$ & $40(72.7)$ & $3(5.5)$ & $* 39(70.9)$ \\
\hline Yoruba & 946 & 82 & $946(82)$ & $694(73.4)$ & $65(6.9)$ & $891(94.2)$ \\
\hline Igbo & 20 & 1.7 & $20(1.7)$ & $17(85.0)$ & $1(5.0)$ & $20(100.0)$ \\
\hline Others & 133 & 11.5 & $\begin{array}{c}133(11.5) \\
\text { Page } 10 / 28\end{array}$ & $88(66.2)$ & $2(1.5)$ & $95(71.4)$
\end{tabular}




\section{Sex Of Household}

Head

\begin{tabular}{|c|c|c|c|c|c|c|}
\hline Male & 946 & 82 & $946(82)$ & $682(72.1)$ & $58(6.1)$ & $858(90.7)$ \\
\hline Female & 208 & 18 & $208(18)$ & $157(75.5)$ & $13(6.3)$ & $187(89.9)$ \\
\hline \multicolumn{7}{|c|}{$\begin{array}{l}\text { Household Wealth } \\
\text { Tertiles }\end{array}$} \\
\hline Lowest & 385 & 33.4 & $385(33.4)$ & $268(69.6)$ & $20(5.2)$ & $\begin{array}{l}* 312 \\
(81.0)\end{array}$ \\
\hline Middle & 385 & 33.4 & $385(33.4)$ & $280(72.7)$ & $23(6.0)$ & $365(94.8)$ \\
\hline Highest & 384 & 33.3 & $384(33.3)$ & $291(75.8)$ & $28(7.3)$ & $368(95.8)$ \\
\hline \multicolumn{7}{|l|}{ Media } \\
\hline No & 174 & 15.1 & $174(15.1)$ & $129(74.1)$ & $10(5.7)$ & $153(87.9)$ \\
\hline Yes & 980 & 84.9 & $980(84.9)$ & $710(72.4)$ & $61(6.2)$ & $892(91.0)$ \\
\hline \multicolumn{7}{|c|}{ Drinking Water Source } \\
\hline Unimproved & 329 & 28.5 & $329(28.5)$ & $93(71.7)$ & $21(6.4)$ & $\star 295(89.7)$ \\
\hline Improved & 825 & 71.5 & $825(71.5)$ & $222(73.1)$ & $50(6.1)$ & 775(93.9) \\
\hline \multicolumn{7}{|c|}{ Open Defecation } \\
\hline No & 702 & 60.8 & $702(60.8)$ & 507 (72.2) & $49(7.0)$ & $\begin{array}{l}* 666 \\
(94.9)\end{array}$ \\
\hline Yes & 452 & 39.2 & $452(39.2)$ & $332(73.5)$ & $22(4.9)$ & $379(83.8)$ \\
\hline
\end{tabular}

\section{Covered By Health}

Insurance

\begin{tabular}{lllllll} 
No & 1,138 & 98.6 & $1138(98.6)$ & $827(72.7)$ & $69(6.1)$ & $\begin{array}{l}1029 \\
(90.4)\end{array}$ \\
\hline Yes & 16 & 1.4 & $16(1.4)$ & $12(75.0)$ & $2(12.5)$ & $16(100.0)$
\end{tabular}

\section{Health Care Autonomy}

\begin{tabular}{lllllll} 
Respondent & 128 & 11.4 & $128(11.4)$ & $* 60(46.9)$ & $\star 5(3.9)$ & $121(94.5)$ \\
\hline Both & 636 & 56.8 & $636(56.8)$ & $519(81.6)$ & $32(5.0)$ & $576(90.6)$ \\
\hline Spouse Alone & 355 & 31.7 & $355(31.7)$ & $240(67.6)$ & $33(9.3)$ & $316(89.0)$
\end{tabular}

\section{Problem with distance to Healthcare}

Not a big problem

$$
650 \quad 56.3 \quad 650(56.3) \quad * 410(63.1) \quad * 60(9.2)
$$


Big problem

504

$43.7 \quad 504(43.7)$

$429(85.1)$

$11(2.2)$

$444(88.1)$

\section{Type Of Place Of} Residence

\begin{tabular}{lllllll}
\hline Urban & 845 & 73.2 & $845(73.2)$ & $624(73.8)$ & $* 62(7.3)$ & $\begin{array}{l}* 789 \\
(93.4)\end{array}$ \\
\hline Rural & 309 & 26.8 & $309(26.8)$ & $215(69.6)$ & $9(2.9)$ & $256(82.8)$ \\
\hline Total & $\mathbf{1 , 1 5 4}$ & $\mathbf{1 0 0}$ & $1154(100)$ & $\mathbf{8 3 9 ( 7 2 . 7 )}$ & $\mathbf{7 1 ( 6 . 2 )}$ & $\mathbf{1 0 4 5 ( 9 0 . 6 )}$
\end{tabular}

*Significant association at $5 \% \mathrm{X}^{2}$ test

Table 2: Prevalence of ever utilization of ORS/Zinc for managing diarrhoea 


\begin{tabular}{|c|c|c|c|}
\hline Characteristics & $\mathrm{n}$ & Ever used ORS/Zinc (\%) & $X^{2} p$-value \\
\hline \multicolumn{4}{|l|}{ Maternal Age (years) } \\
\hline $15-19$ & 14 & $0(0.0)$ & 0.000 \\
\hline $20-24$ & 160 & $13(8.1)$ & \\
\hline $25-29$ & 324 & $34(10.5)$ & \\
\hline $30-39$ & 525 & $12(2.3)$ & \\
\hline $40-49$ & 131 & $3(2.3)$ & \\
\hline \multicolumn{4}{|l|}{ Marital status } \\
\hline Never Married & 20 & $0(0.0)$ & 0.348 \\
\hline Living with sexual partner & 1118 & $62(5.5)$ & \\
\hline Formerly & 16 & $0(0.0)$ & \\
\hline \multicolumn{4}{|l|}{ Maternal Education } \\
\hline None & 172 & $1(0.6)$ & 0.009 \\
\hline Primary & 201 & $11(5.5)$ & \\
\hline Secondary+ & 781 & $50(6.4)$ & \\
\hline \multicolumn{4}{|l|}{ Religion } \\
\hline Catholic & 536 & $36(6.7)$ & 0.213 \\
\hline Islam & 618 & $26(4.2)$ & \\
\hline \multicolumn{4}{|l|}{ Tribe } \\
\hline Hausa/Fulani & 55 & $1(1.8)$ & 0.083 \\
\hline Yoruba & 946 & $54(5.7)$ & \\
\hline Igbo & 20 & $3(15.0)$ & \\
\hline Others & 133 & $4(3.0)$ & \\
\hline \multicolumn{4}{|l|}{ Sex of Household Head } \\
\hline Male & 946 & $52(5.5)$ & 0.690 \\
\hline Female & 208 & $10(4.8)$ & \\
\hline \multicolumn{4}{|l|}{ Household Wealth Tertiles } \\
\hline Lowest & 385 & $16(4.2)$ & 0.354 \\
\hline Middle & 385 & $25(6.5)$ & \\
\hline
\end{tabular}


Highest

\section{Media Access}

No

Yes

Drinking Water Source

Unimproved

Improved

Open Defecation

$\begin{array}{llll}\text { No } & 702 & 39(5.6) & 0.731 \\ \text { Yes } & 452 & 23(5.1) & \end{array}$

Covered By Health Insurance

No

Yes

Health Care Autonomy

Respondent

Both

Spouse Alone

Problem with distance to HF Healthcare

Not a big problem

Big problem

Type of Place of Residence

Urban

Rural

Total

$174 \quad 10(5.7)$

$980 \quad 52(5.3)$

$329 \quad 19(5.8)$

$825 \quad 43(5.2)$
$1138 \quad 58(5.1) \quad 0.000$

$164(25.0)$

$128 \quad 5(3.9) \quad \mathbf{0 . 0 0 2}$

$636 \quad 25(3.9)$

$355 \quad 32(9.0)$

\begin{tabular}{lll}
650 & $45(6.9)$ & $\mathbf{0 . 0 0 8}$ \\
504 & $17(3.4)$ & \\
& & 0.443 \\
\hline 845 & $48(5.7)$ & \\
309 & $14(4.5)$ & \\
1154 & $62(5.4)$ &
\end{tabular}

*Significant at $5 \%$ level of chi-square; HF Health facility

Table 3: Distribution of ORS or Zinc utilization in diarrhoea management 


\section{Characteristics}

$\begin{array}{llllll}n & \begin{array}{l}\text { Used } \\ \text { something }\end{array} & \begin{array}{l}\text { Used } \\ \text { ORS }\end{array} & \begin{array}{l}\text { Used } \\ \text { Zinc }\end{array} & \begin{array}{l}\text { Used } \\ \text { either }\end{array} & \begin{array}{l}\text { Used } \\ \text { both }\end{array} \\ n n(\%) & n(\%) & n(\%) & n(\%) & n(\%)\end{array}$

\section{Child Age}

0 to 6 Months

$8 \quad 5(62.5)$

$3(37.5) \quad 2(25.0) \quad 4(50.0)$

$1(12.5)$

7 to 23 Months

$37 \quad 24(64.9)$

23

(62.2)

$\begin{array}{ll}15 & 25(67.6)\end{array}$

13

(35.1)

24 to 59 Months

$26 \quad 10(38.5)$

12

$5(19.2)$

$12(46.2) \quad 5(19.2)$

\section{Sex Of Child}

Male

$41 \quad 24(58.5)$

$\begin{array}{ll}21 & 15 \\ (51.2) & (36.6)\end{array}$

$23(56.1) \quad 13$

17

Female

$30 \quad 15(50.0)$

17

(56.7)

$7(23.3) \quad 18(60.0) \quad 6(20.0)$

\section{Birth Order}

$$
1
$$

2

3

$4+$

\section{Dejure U5C in $\mathrm{HH}$}

\begin{tabular}{lllllll} 
& 27 & $18(66.7)$ & $\begin{array}{l}12 \\
(44.4)\end{array}$ & $\begin{array}{l}11 \\
(40.7)\end{array}$ & $14(51.9)$ & $9(33.3)$ \\
\hline 2 & 35 & $16(45.7)$ & $\begin{array}{l}19 \\
(54.3)\end{array}$ & $7(20.0)$ & $20(57.1)$ & $6(17.1)$ \\
\hline 3 & 9 & $5(55.6)$ & $7(77.8)$ & $4(44.4)$ & $7(77.8)$ & $4(44.4)$ \\
\hline Maternal Age (years) & & & & & & \\
\hline $20-24$ & 11 & $9(81.8)$ & $\begin{array}{l}* 9 \\
(81.8)\end{array}$ & $4(36.4)$ & $* 9(81.8)$ & $4(36.4)$ \\
\hline $25-29$ & 31 & $14(45.2)$ & $\begin{array}{l}19 \\
(61.3)\end{array}$ & $9(29.0)$ & $21(67.7)$ & $7(22.6)$ \\
\hline $30-39$ & 23 & $13(56.5)$ & $8(34.8)$ & $8(34.8)$ & $9(39.1)$ & $7(30.4)$ \\
\hline $40-49$ & 6 & $3(50.0)$ & $2(33.3)$ & $1(16.7)$ & $2(33.3)$ & $1(16.7)$
\end{tabular}

$\begin{array}{llllll}10 & * 9(90.0) & 7(70.0) & \begin{array}{l}* 5 \\ (50.0)\end{array} & * 7(70.0) & 5(50.0) \\ 18 & 11(61.1) & \begin{array}{l}10 \\ (55.6)\end{array} & 9(50.0) & 13(72.2) & 6(33.3) \\ 23 & 13(56.5) & \begin{array}{l}15 \\ (65.2)\end{array} & 5(21.7) & 15(65.2) & 5(21.7) \\ 20 & 6(30.0) & 6(30.0) & 3(15.0) & 6(30.0) & 3(15.0)\end{array}$




\section{Marital status}

Never Married

Living with sexual partner

$\begin{array}{llllll}1 & 1(100.0) & 0(0.0) & 0(0.0) & 0(0.0) & 0(0.0) \\ 70 & 38(54.3) & 38 & 22 & 41(58.6) & 19 \\ & & (54.3) & (31.4) & & (27.1)\end{array}$

\section{Maternal Education}

None

Primary

Secondary+

\section{Partner Education}

None

Primary

Secondary+

\section{Religion}

Catholic

Islam

\section{Tribe}

Others

Yoruba

\section{Sex of Household Head}

Male

Female

Household Wealth Tertiles

Lowest

Middle

Highest

$$
32 \quad 15(46.9)
$$

$39 \quad 24(61.5)$

\begin{tabular}{llllll}
3 & $2(66.7)$ & $1(33.3)$ & $1(33.3)$ & $1(33.3)$ & $1(33.3)$ \\
\hline 10 & $6(60.0)$ & $6(60.0)$ & $2(20.0)$ & $6(60.0)$ & $2(20.0)$ \\
58 & $31(53.4)$ & $\begin{array}{l}31 \\
(53.4)\end{array}$ & $\begin{array}{l}19 \\
(32.8)\end{array}$ & $34(58.6)$ & 16 \\
& & & $(27.6)$
\end{tabular}

$42(50.0)$

$1(25.0) \quad 1(25.0) \quad 1(25.0) \quad 1(25.0)$

$7 \quad 5(71.4)$

$4(57.1)$

$59 \quad 31(52.5)$

33

$(55.9)$

20

(62.5)

11

(34.4)

$21(65.6) \quad 10$

18

(46.2)
$4(57.1) \quad 0(0.0)$

$36(61) \quad 18$

(30.5)
11

(28.2)

$\begin{array}{llllllll}\text { Middle } & 23 & 12(52.2) & \begin{array}{l}13 \\ (56.5)\end{array} & 7(30.4) & 14(60.9) & 6(26.1) \\ \text { Highest } & 28 & 15(53.6) & \begin{array}{l}15 \\ (53.6)\end{array} & 8(28.6) & 17(60.7) & 6(21.4)\end{array}$

$\begin{array}{llllll}6 & 4(66.7) & 4(66.7) & 3(50.0) & 4(66.7) & 3(50.0) \\ 65 & 35(53.8) & 34 & 19 & 37(56.9) & 16 \\ & & (52.3) & (29.2) & & (24.6)\end{array}$

$58 \quad 29(50.0)$

$31 \quad * 15 \quad 33(56.9) \quad 13$

(53.4) (25.9)

(22.4)

$13 \quad 10(76.9)$

$7(53.8) \quad 7(53.8) \quad 8(61.5) \quad 6(46.2)$ 


$\begin{array}{lllllll}\text { No } & 10 & 7(70.0) & 6(60.0) & 3(30.0) & 7(70.0) & 2(20.0) \\ \text { Yes } & 61 & 32(52.5) & 32 & 19 & 34(55.7) & 17 \\ & & & (52.5) & (31.1) & & (27.9)\end{array}$

\section{Covered By Health Insurance}

$\begin{array}{lllllll}\text { No } & 69 & 38(55.1) & 36 & 21 & 39(56.5) & 18 \\ & & & (52.2) & (30.4) & & (26.1) \\ \text { Yes } & 2 & 1(50.0) & \begin{array}{l}2 \\ (100.0)\end{array} & 1(50.0) & 2(100.0) & 1(50.0)\end{array}$

\section{Health Care Autonomy}

\begin{tabular}{lllllll} 
Respondent & 5 & $* 2(40.0)$ & $3(60.0)$ & $1(20.0)$ & $3(60.0)$ & $1(20.0)$ \\
\hline Both & 32 & $25(78.1)$ & $\begin{array}{l}17 \\
(53.1)\end{array}$ & $\begin{array}{l}14 \\
(43.8)\end{array}$ & $20(62.5)$ & 11 \\
Spouse Alone & 33 & $11(33.3)$ & $\begin{array}{l}18 \\
(54.5)\end{array}$ & $7(21.2)$ & $18(54.5)$ & $7(21.2)$
\end{tabular}

\section{Problem with distance to Healthcare}

\begin{tabular}{lllllll} 
Not a big problem & 60 & $30(50.0)$ & $\begin{array}{l}* 29 \\
(48.3)\end{array}$ & $\begin{array}{l}16 \\
(26.7)\end{array}$ & $32(53.3)$ & $\begin{array}{l}* 13 \\
(21.7)\end{array}$ \\
\hline Big problem & 11 & $9(81.8)$ & $9(81.8)$ & $6(54.5)$ & $9(81.8)$ & $6(54.5)$
\end{tabular}

\section{Type of Place of Residence}

\begin{tabular}{lllllll}
\hline Urban & 62 & $32(51.6)$ & $\begin{array}{l}31 \\
(50.0)\end{array}$ & $\begin{array}{l}18 \\
(29.0)\end{array}$ & $34(54.8)$ & $\begin{array}{l}15 \\
(24.2)\end{array}$ \\
\hline Rural & 9 & $7(77.8)$ & $7(77.8)$ & $4(44.4)$ & $7(77.8)$ & $4(44.4)$ \\
\hline Total & $\mathbf{7 1}$ & $\mathbf{3 9 ( 5 4 . 9 )}$ & $\mathbf{3 8 ( 5 3 . 5 )}$ & $\mathbf{2 2}$ & $\mathbf{4 1 ( 5 7 . 7 )}$ & $\mathbf{1 9}$ \\
& & & & $\mathbf{( 3 1 . 0 )}$ & & $\mathbf{( 2 6 . 8 )}$
\end{tabular}

*Significant at $5 \%$ level of chi-square; HF Health facility

The unadjusted odds of using ORS/Zinc in managing diarrhoea was 6 times (OR $=5.84 ; 95 \%$ Cl: $1.84-$ 28.53), 5 times (OR = 4.92; 95\% Cl: $1.77-11.07)$, and 4 times (OR=4.28; 95\% Cl: 1.21 - 10.81) more likely among mothers whose child had first, second and third birth order respectively than those with fourth or higher birth orders (table 4). The odds of using ORS/Zinc in managing diarrhoea was 8 times (OR= 8.44; $95 \% \mathrm{Cl}: 1.46-28.85)$ among mothers aged 20 to 24 years and 4 times (OR= 3.97; 95\% Cl: $1.97-9.12)$ among children of mothers aged 25 to 29 years than those aged 30 to 34 years. In the multivariable model, while controlling for other variables, the adjusted odds of using ORS/Zinc to manage diarrhoea was $2.64(\mathrm{aOR}=2.64 ; 95 \%$ Confidence Interval $(\mathrm{Cl}): 1.18$ - 10.27) times higher among children who are the first births (first-order) than those with fourth birth order or higher. The adjusted odds of using 
ORS/Zinc to manage diarrhoea was 9 times ( $\mathrm{aOR}=9.15 ; 95 \% \mathrm{Cl}: 1.99-34.47$ ) higher among mothers aged 20 to 24 years and 3.82 times (aOR=3.82; 95\% Cl: $1.02-14.27$ ) higher among mothers aged 25 to 29 years than those aged 30 to 39 years. The adjusted odds of using ORS/Zinc to manage diarrhoea was lower (aOR= $0.07 ; 95 \% \mathrm{Cl}: 0.01-0.72)$ among children whose mothers had no big problem accessing healthcare services compared with those that problems getting to health care facilities.

Table 4: Factors associated with the use of ORS in managing diarrhoea 


\section{Characteristics}

\section{Child Age}

0 to 6 Months

7 to 23 Months

24 to 59 Months

\section{Sex of Child}

Male

Female

\section{Birth Order}

\begin{tabular}{lll}
\hline 1 & $\mathbf{5 . 8 4}(\mathbf{1 . 8 4}-\mathbf{2 8 . 5 3})$ & $\mathbf{2 . 6 4}(\mathbf{1 . 1 8}-\mathbf{1 0 . 2 7})$ \\
\hline 2 & $\mathbf{4 . 9 2 ( 1 . 7 7 - 1 1 . 0 7 )}$ & $2.51(0.37-8.86)$ \\
\hline 3 & $\mathbf{4 . 2 8 ( 1 . 2 1 - 1 0 . 8 1 )}$ & $2.43(0.53-11.07)$ \\
\hline Maternal Age (years) & Reference & \\
\hline $20-24$ & & $\mathbf{9 . 1 5}(1.99-\mathbf{3 4 . 4 7})$ \\
\hline $25-29$ & $\mathbf{8 . 4 4}(1.46-\mathbf{2 8 . 8 5})$ & $\mathbf{3 . 8 2}(\mathbf{1 . 0 2}-\mathbf{1 4 . 2 7})$ \\
\hline $30-39$ & $\mathbf{3 . 9 7}(\mathbf{1 . 9 7 - 9 . 1 2 )}$ & \\
\hline $40-49$ & Reference & $0.37(0.02-6.66)$ \\
\hline Maternal Education & $0.94(0.14-6.28)$ & \\
\hline None & & N/A \\
\hline Primary & Reference & \\
\hline Secondary+ & $3.00(0.20-45.24)$ & N/A \\
\hline Religion & $2.30(0.20-26.75)$ & \\
\hline Catholic & & \\
\hline Islam & $0.51(0.20-1.33)$ & \\
\hline
\end{tabular}

\section{Tribe}

Others

Yoruba

Sex of Household Head
Crude Odds Ratio (95\%

Cl)

Adjusted Odds Ratio (95\%

Cl)

$2.74(0.57-13.27)$

$1.43(0.28-7.26) \quad \quad$ N/A

Reference

Reference

$1.25(0.48-3.21) \quad$ N/A

$5.84(1.84-28.53) \quad 2.64(1.18-10.27)$

$4.92(1.77-11.07) \quad 2.51(0.37-8.86)$

$4.28(1.21-10.81) \quad 2.43(0.53-11.07)$

Reference

$8.44(1.46-28.85) \quad 9.15(1.99-34.47)$

$3.97(1.97-9.12)$

$3.82(1.02-14.27)$

Reference

Reference

Reference

$2.19(0.19-25.4) \quad N / A$ 


\begin{tabular}{|lll|}
\hline Male & Reference & $0.91(0.21-3.89)$ \\
\hline Female & $1.02(0.30-3.4)$ & \\
\hline Household Wealth Tertiles & & N/A \\
\hline Lowest & Reference & \\
\hline Middle & $1.30(0.39-4.33)$ & \\
\hline Medighest & $1.15(0.37-3.64)$ & N/A \\
\hline No & & \\
\hline Yes & Reference & N/A \\
\hline Health Care Autonomy & $0.74(0.19-2.87)$ & \\
\hline Respondent & & \\
\hline Both & $1.25(0.18-8.49)$ & \\
\hline Spouse Alone & $0.94(0.36-2.51)$ & $0.07(0.01-0.72)$ \\
\hline Problem with distance to HF & Reference & \\
\hline Healthcare & & \\
\hline Not a big problem & Reference & \\
\hline Big problem & $3.50(0.67-18.20)$ & \\
\hline Type of Place of Residence & $4.81(0.96-24.15)$ & \\
\hline Urban & & \\
\hline Rural & & \\
\hline
\end{tabular}

\section{Discussion}

This study was designed to evaluate the knowledge of the symptoms of diarrhoea, awareness, utilization and factors associated with the utilization of use of ORS/zinc in managing diarrhoea among U5C in Oyo State, Nigeria. The results showed a very high level of knowledge of the symptoms of diarrhoea and awareness of the use of ORS/Zinc for managing diarrhoea cases among U5C. Nine of every ten women interviewed claimed to have heard about the use of ORS/Zinc for managing diarrhoea. The level varied by maternal age, maternal education, partner's education, tribe, household wealth tertiles, open defecation, and having a problem with distance to healthcare services and place of residence. The result in this study was comparable with what exists in the literature [24-26]. Similarly, Riaz et al. found that a good percentage of mothers had good knowledge of the purpose of ORS use (78\%) [24]. The authors found that only $39 \%$ of mothers had good knowledge about the use of zinc for managing diarrhoea. They 
reported that the level of awareness of the use of ORS and Zinc varied by the respondents' characteristics [24]. The current study showed a huge disparity in the level of awareness of ORS/Zinc as means of treating diarrhoea increased by educational attainment and by having health insurance coverage.

The two medical doctors interviewed stated that they prescribed ORS and Zinc for diarrhoea management. This aligned with the reports of Omuemu et al. that two-thirds of the 168 health care workers who participated in the study were aware of zinc supplementation but specific knowledge of zinc supplementation in the management of childhood acute diarrhoea was poor [26]. Omuemu et al. reported that all but one of the participants prescribed zinc in addition to ORS [26].

While the overall prevalence of ever-use of ORS/Zinc for managing diarrhoea cases among U5C stood at less than $6 \%$, the current utilization among mothers whose children had diarrhoea within two weeks preceding the data collection was $54 \%$. It is worth noting that $45 \%$ of the mothers whose children had diarrhoea within two weeks preceding the data collection did not use anything to treat the diarrhoea episode. This is very worrisome as this constitutes a great risk to the health of the vulnerable U5C. A similarly low level of diarrhoea management using ORS and Zinc has been reported. For instance, Akinyemi et al. reported only 34\% utilization of ORS for diarrhoea management, [27] while Riaz et al. found that a good percentage of mothers in their study initiated the use of ORS (68\%) [24]. Compared with the findings that a total of 22 of the 71 mothers who reported recent episodes of diarrhoea among their U5C claimed to have used Zinc to manage the episode, and $27 \%$ combining both ORS and Zinc, Akinyemi et al. reported only $2 \%$ for Zinc and a lowly $1 \%$ for joint utilization of both [27]. Also, Riaz et al. found that the daily administration of Zinc was only done by one of every five of the mothers in their study [24].

Carvajal et al., in a study entitled "Diarrhea management in children under five in sub-Saharan Africa" reported that the prevalence of good diarrhoea management is low in 11 of the 12 countries included in the analysis except for Sierra Leone[15]. The study showed that the prevalence varied from $17 \%$ in Cote d'Ivoire to $38 \%$ in Niger and $67 \%$ in Sierra Leone [15]. The prevalence of ever use of ORS/Zinc for managing diarrhoea cases was significantly associated with the level of awareness of the use of ORS/Zinc for managing diarrhoea cases among U5C were maternal age, maternal education, partner's education, health insurance, healthcare autonomy, and having a problem with distance to healthcare services. However, the only significant characteristics associated with the current prevalence of use of ORS in managing diarrhoea cases among U5C were maternal age and having problems with getting to healthcare centres. Similar assertions have been made in the literature. Just as found in the current study, although insignificant, utilization of ORS and Zinc in managing diarrhoea increased with mothers' educational attainment, Riaz et al. found that more educated mothers had higher utilization of ORS and Zinc [24]. Similarly, Akinyemi et al. found higher utilization among urban dwellers, people with unimproved sources of water, household wealth quintile [27]. However, due to the low power of the models as a result of the limited sample size, as the data of only the 71 mothers whose children had a recent episode of diarrhoea were eligible for inclusion in the models, only a few variables were significant in the multivariable model, while controlling for other variables. These significant characteristics are the 
ages of the children, the mothers' age, and whether the mothers had problems accessing healthcare services compared with those that had problems getting to health care facilities.

Only 71 of the 1154 study participants in the quantitative arm reported an episode of diarrhoea within the two weeks that preceded the data collection. Hence only these participants were included in the models. This resulted in wide confidence intervals and made some well-known influencers of the uptakes of ORS to be insignificant. Another limitation is recall bias. However, a major strength of this study is the combination of both qualitative data and quantitative data.

\section{Strength and Limitation}

A major strength of this study is the combination of both qualitative data and quantitative data. The outcome of the KIls and the FGDs in the qualitative aspect of the study design gave credence to the outcomes of the quantitative arm. However, only 71 of the 1154 study participants in the quantitative arm reported an episode of diarrhoea within the two weeks that preceded the data collection. This resulted in wide confidence intervals and made some well-known influencers of the uptakes of ORS to be insignificant. Also, the responses were based on respondents' ability to correctly recall past events, this might have caused bias. However, the efforts were made by interviewers to aid the respondents to provide accurate responses.

\section{Recommendations}

For adequate utilization of ORS and Zinc for effective management of diarrhoea cases among U5C in the study area, there is need for quick and decisive steps to increase awareness and utilization of ORS and Zinc. The ministry of health and other stakeholders should review and strengthen the existing health education and promotion on the usefulness and effectiveness of ORS and Zinc in managing diarrhoea. Policymakers should design evidence-based, community-feasible and community-suitable interventions to improve the utilization of ORS and Zinc in managing diarrhoea.

\section{Conclusion}

Although there are high levels of awareness of the symptoms of diarrhoea among mothers in the study area and high levels of awareness of ORS and Zinc in the management of diarrhoea but the utilization of ORS and Zinc in the management of diarrhoea is low compared with the national average of $16.1 \%$ in 2018 [23]. Besides, some mothers cannot afford the commodity when it is unavailable in government hospitals. The associated factors with the utilization of these commodities are the children age, birth order, maternal age, maternal educational attainment, having a big problem accessing healthcare services and the places of residence of the children.

\section{Abbreviations}




\begin{tabular}{ll} 
FGD & Focus Group Discussion \\
\hline GBD & Global Burden of Diseases \\
\hline KII & Key Informant Interview \\
\hline ORS & Oral rehydration salt \\
\hline ORT & Oral rehydration therapy \\
\hline RHF & Government-Recommended Homemade Fluids \\
\hline SSA & Sub Saharan African \\
\hline UNICEF & United Nations Children Fund \\
\hline UN & United Nations \\
\hline U5C & Under five children \\
\hline WHO & World Health Organization
\end{tabular}

\section{Declarations}

\section{Ethics approval and consent to participate}

The study was granted ethical approval by the Oyo State Ministry of Health with approval number AD/ 13/479/1696. All participants and their legal guardian/next of kin provided written informed consent to participate in this study. All methods were performed in accordance with the relevant guidelines and regulations ethical approving authority.

\section{Consent for publication}

Not applicable

\section{Availability of data and materials}

The datasets generated and/or analysed during the current study are not publicly available due to restrictions from ethical approvals but are available from the corresponding author on reasonable request

\section{Competing interests}

The authors declared no conflict of interest

\section{Funding}

Authors received no funding for this study

\section{Authors' contributions}


AFF contributed to conception and study design and conducted the statistical analysis and interpretation of results and the drafting of the manuscripts. AFF, JJ, AO, DM and JK reviewed the statistical analysis and revised the manuscript draft. All authors read and approved the final manuscript.

\section{Acknowledgements}

The authors acknowledge the study participants: mothers and guardians of the under-five children, the children, the pediatricians, the staff of Ministry of health of Oyo State Nigeria as well as the staff and students of Mount Kenya University, Nairobi.

\section{Authors' information (optional)}

Adeniyi Francis Fagbamigbe is an MPH student at the Department of Epidemiology \& Biostatistics, School of Public Health, Mount Kenya University, Nairobi, Kenya and a faculty member at the Department of Epidemiology and Medical Statistics, Faculty of Public Health, College of Medicine, University of Ibadan, Ibadan, Nigeria. Juma Joseph, Alfred Owino, Dominic Mogere and John Kariuki are faculty members at the Department of Epidemiology \& Biostatistics, School of Public Health, Mount Kenya University, Nairobi, Kenya

\section{References}

1. GBD 2016 Diarrhoeal Disease Collaborators. Estimates of the global, regional, and national morbidity, mortality, and aetiologies of diarrhoea in 195 countries: a systematic analysis for the Global Burden of Disease Study 2016. Lancet Infect Dis. 2018;18:1211-28. doi:10.1016/S1473-3099(18)30362-1.

2. Gill CJ, Thea DM, Hibberd P. Diarrhoeal disease trends in the GBD 2015 study: optimism tempered by scepticism. Lancet Infect Dis. 2017;17:884-5. doi:10.1016/S1473-3099(17)30336-5.

3. Wilson ME. Global Burden from Diarrhea: Decreasing but Still a Leading Cause of Death. NEJM Journal Watch. 2017;2017:1. doi:10.1056/NEJM-JW.NA44326.

4. Benue State Government of Nigeria. Push Diarrhea Away. Shop Plus Project. 2018. https://www.shopsplusproject.org/article/push-diarrhea-away-campaign-reaches-30000-benue-state. Accessed 5 Mar 2019.

5. WHO. Clinical Management of acute diarrhoea: WHO/UNICEF joint statement. Geneva, Switzerland; 2004. http://www.who.int/iris/handle/10665/68627.

6. Black RE. Progress in the use of ORS and zinc for the treatment of childhood diarrhea. J Glob Heal. 2019;9:10-2.

7. Schroder K, Battu A, Wentworth L, Houdek J, Fashanu C, Wiwa O. Increasing coverage of pediatric diarrhea treatment in high-burden countries. J Glob Heal. 2019;9:1-5. 
8. Clinton Health Access Initiative. Zinc/ORS Scale-up in Nigeria. New York; 2016.

9. Lenters LM, Das JK, Bhutta ZA. Systematic review of strategies to increase use of oral rehydration solution at the household level. BMC Public Health. 2013;13 Suppl 3:s28:1-8.

10. Lazzerini M, Wanzira H. Oral zinc for treating diarrhoea in children. Cochrane Database Syst Rev. 2016;12:CD005436.

11. Walker FCL, Rudan I, Liu L, Nair H, Theodoratou E, Bhutta ZA, et al. Global burden of childhood pneumonia and diarrhoea. Lancet. 2013;381:1405-16. doi:10.1016/S0140-6736(13)60222-6.

12. WHO. Diarrhoeal Disease. Geneva; 2017. http://www.who.int/ mediacentre/factsheets/fs330/en/.

13. Onwukwe S, van Deventer C, Omole O. Evaluation of the use of oral rehydration therapy in the management of diarrhoea among children under 5: knowledge attitudes and practices of mothers/caregivers. South African Fam Pract. 2016;58:42-7. doi:10.1080/20786190.2015.1120933.

14. Wagner Z, Shah M, Sood N. Barriers to use of oral rehydration salts for child diarrhea in the private sector: Evidence from India. J Trop Pediatr. 2015;61:37-43. doi:10.1093/tropej/fmu063.

15. Carvajal-vélez L, Amouzou A, Perin J, Maïga A, Tarekegn H, Akinyemi IA, et al. Diarrhea management in children under five in sub-Saharan Africa: does the source of care matter? A Countdown analysis. BMC Public Health. 2016;16:1-14.

16. Andersen RM. A behavioral Model of Families' Use of Health Services. Research Series No. 25. Chicago, IL; 1968.

17. Andersen RM. Revisiting the behavioral model and access to medical care: Does it matter? Journal of Health and Social Behavior. 1995;36:1-10.

18. Wolinsky F. Seeking and Using Health Services. In The Sociology of Health. 2nd ed. Belmont, Canada: Wadsworth; 1988.

19. Aday L, Andersen RM. A framework for the study of access to medical care. Health Serv Res. 1974;9:208-20.

20. Babitsch B, Gohl D, von Lengerke T. Das Verhaltensmodell der Inanspruchnahme gesundheitsbezogener Versorgung von Andersen re-revisited: Ein systematischer Review von Studien zwischen 1998-2011. GMS Psycho-Social-Medicine. 2012;9. doi:10.3205/psm000089.

21. Cummings GG, Reid RC, Estabrooks CA, Norton PG, Cummings GE, Rowe BH, et al. Older persons' transitions in care (OPTIC): A study protocol. BMC Geriatr. 2012;12.

22. Ghimire PR, Agho KE, Renzaho AMN, Dibley M, Raynes-Greenow C. Association between health service use and diarrhoea management approach among caregivers of under-five children in Nepal. PLoS 
One. 2018;13:e0191988. doi:10.1371/journal.pone.0191988.

23. National Population Commission(NPC)[Nigeria], ICF International. Nigeria Demographic and Health Survey 2018. Abuja, Nigeria, And Rockville, Maryland, USA; 2019.

24. Riaz N, Tul Muntaha S, Qibtia M, Sohail S. Use of Zinc and Oral Rehydration Solution in Home Management of Diarrhea: Knowledge of Mothers attending a Tertiary Care Hospital. J Islam Med Dent. 2019;8:135-40. doi:10.35787/jimdc.v8i3.419.

25. Lamberti LM, Fischer Walker CL, Taneja S, Mazumder S, Black RE. The Association between Provider Practice and Knowledge of ORS and Zinc Supplementation for the Treatment of Childhood Diarrhea in Bihar, Gujarat and Uttar Pradesh, India: A Multi-Site Cross-Sectional Study. PLoS One. 2015;10:e0130845. doi:10.1371/journal.pone.0130845.

26. Omuemu VO, Ofuani IJ, Kubeyinje IC. Knowledge and use of zinc supplementation in the management of childhood diarrhoea among health care workers in public primary health facilities in Benin-City, Nigeria. Glob J Health Sci. 2012;4:68-76. doi:10.5539/gjhs.v4n2p68.

27. Akinyemi IA, Fagbamigbe AF, Omoluabi E, Agunbiade OM, Adebayo SO. Diarrhoea Management Practices and Child Health Outcomes in Nigeria: Sub-National Analysis. Adv Integr Med. 2018;5:15-22. doi:10.1016/j.aimed.2017.10.002.

\section{Figures}




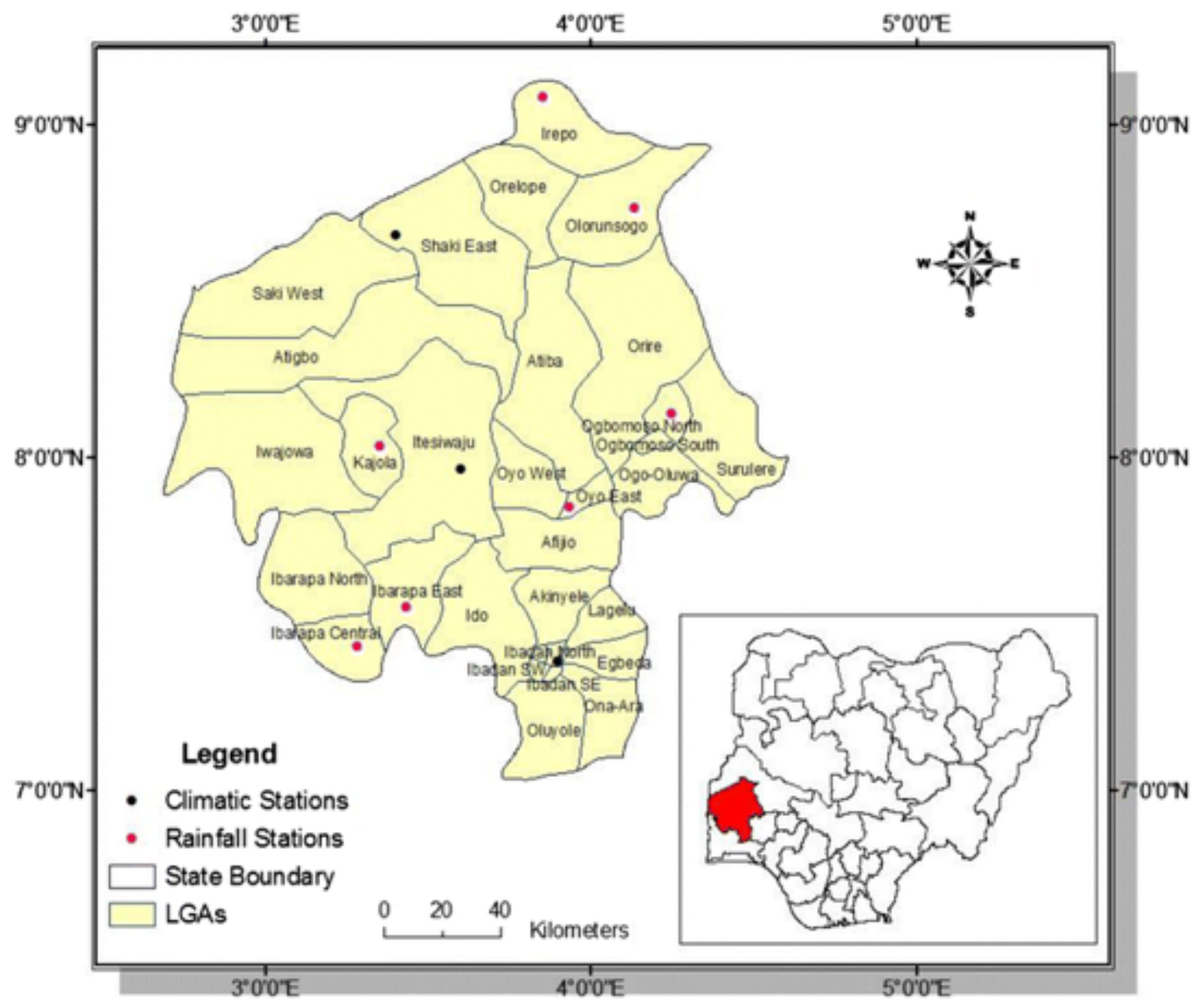

Figure 1

Map of Oyo State showing its location in Nigeria 


\section{Independent Variable}

Knowledge of ORT / Zinc

- Knowledge of symptoms of diarrhoea

- Knowledge of ORT/Zinc

- Knowledge of where to get ORT/Zinc

Maternal/Household

Factors

- Maternal Age, Marital status

- Religion, Tribe

- Maternal education

- Maternal employment

\section{Children Characteristics}

- Birth order

- Child age

- Child sex

\section{Community Characteristics}

- Distance to health facility

- Type of residence

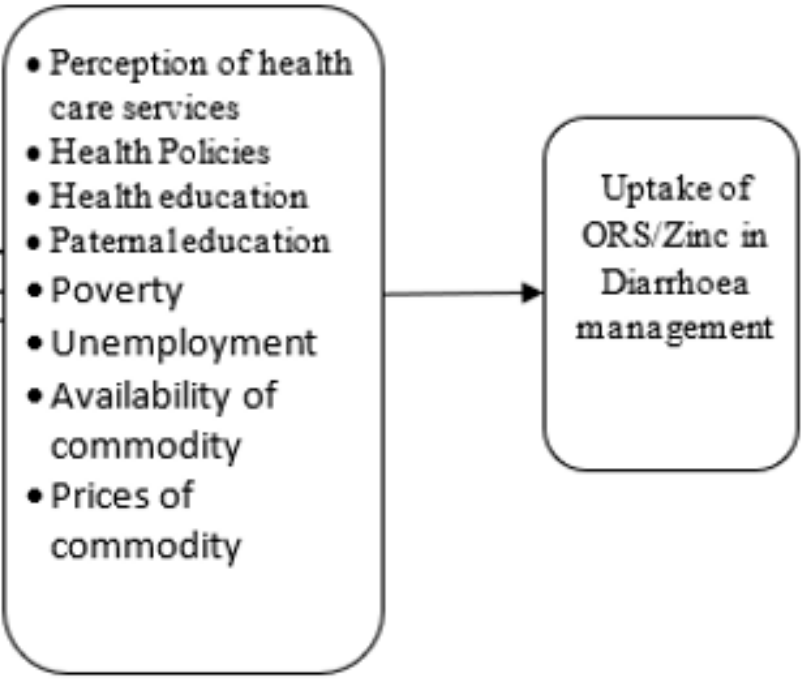

\section{Figure 2}

Conceptual framework for the study 